\title{
Análisis exploratorio de la variabilidad de la cerámica de superficie en el sitio El Carmen 2 (valle de Santa María, Tucumán)
}

Agustina Longo* y Javier Nastri **
Recibido:

30 de marzo de 2017

Aceptado:

17 de noviembre de 2017

\section{Resumen}

En este trabajo se realiza una caracterización de la cerámica de superficie del sitio El Carmen 2 (valle de Santa María, provincia de Tucumán) con el fin de obtener un primer panorama acerca del repertorio de variantes producidas y usadas por los ocupantes del asentamiento a lo largo del tiempo. A partir del análisis macroscópico y submacroscópico y la aplicación de técnicas estadísticas de análisis multivariado (cluster analysis) se realiza el agrupamiento de 289 familias de fragmentos vinculando las tres dimensiones de análisis constitutivas de la cerámica: tratamiento de superficie, pasta y morfología. Teniendo en cuenta el conocimiento existente acerca de los rangos de vigencia temporal de los estilos alfareros reconocidos en la muestra, se discuten las implicancias de la mayor o menor homogeneidad cronológica observable en los grupos generados, así como también la asociación dentro de los mismos de los casos diagnósticos con otros menos conocidos hasta el momento.

\section{Exploratory analysis of the variability of surface ceramics at El Carmen 2 site (Santa María Valley, Tucumán)}

\footnotetext{
Abstract

This article presents a characterisation of surface ceramics collected from the El Carmen 2 site, (Santa María Valley, Tucumán Province, Argentina). The aim is to present a preliminary insight concerning the repertoire of variants produced and used by the occupants of the settlement over time. Based on the macroscopic and sub-macroscopic analyses as well as the application of statistical techniques of multivariate analysis (cluster analysis), the grouping of 289 families of fragments was carried out, linking three aspects constitutive of ceramics - surface treatment, paste and morphology. Taking into consideration the existing knowledge concerning the temporal ranges of the pottery styles recognized in the sample, we discuss the implications of the greater and lesser chronological homogeneity observed in the generated groups. We also assess the association within the same of the diagnostic ceramic vis-à-vis less known styles.

* Facultad de Ciencias Naturales y Museo, Universidad Nacional de La Plata (UNLP). Calles 122 y 60 (CP B190oFWA) La Plata, Buenos Aires, Argentina. E-mail: agustinalongo@fcnym.unlp.edu.ar

** Departamento de Ciencias Naturales y Antropológicas, Centro de Estudios Biomédicos, Biotecnológicos, Ambientales y de Diagnóstico (CEBBAD), Universidad Maimónides. Hidalgo 775 (CP C1405BCK) Ciudad Autónoma de Buenos Aires, Argentina. E-mail: nastri.javier@maimonides.edu
}

\section{Palabras clave}

Cerámica

Análisis multivariado

Valle de Santa María

Primer y segundo milenio d.C.

Keywords

Pottery

Multivariate analysis

Santa María Valley

First and second millennium A.D. 


\section{Introducción}

El sitio El Carmen 2 se encuentra ubicado en el sector centro-occidental del valle de Santa María emplazado a unos 2.400 m s.n.m. en la Sierra del Cajón (Tafí del Valle, Tucumán) (Figura 1). Adyacentes al río, sobre la ladera sur de la quebrada del Carmen, en un área de aproximadamente 6 ha, se disponen un conjunto de 10 Unidades Arquitectónicas (UA) integradas cada una de ellas por uno o más componentes adosados (Figura 2B). Se identificaron dos UA habitacionales formadas por un recinto mayor con probable función de patio al que se adosan recintos menores que podrían haber funcionado como dormitorios, cocinas y/o estructuras de almacenaje. La UA4 presenta planta cuadrangular y la UA2 una planta combinada circular/subcircular/subcuadrangular. Asimismo, se relevaron UA compuestas por un recinto simple de planta cuadrangular con terrazas adosadas por un muro con probable funcionalidad agrícola-ganadera (UA1), un mortero fijo (UA3), hileras de piedras que indican la planta de probables recintos circulares (UA8, UA9, UA10) y estructuras aterrazadas de posible producción agrícola o espacios de cultivo (UA5, UA6, UA7) (Álvarez Larrain, 2016; Berberián y Nielsen, 1988; Nastri, 1997-1998).

El estudio del espacio habitado por las antiguas poblaciones del valle de Santa María ha tenido como eje las investigaciones llevadas a cabo en los grandes asentamientos de la zona de contacto cerro-conoide del segundo milenio de la Era. Avances recientes han aportado datos respecto de ocupaciones más tempranas en el fondo del valle (e.g. Scattolin et al., 2001), así como en las laderas occidentales de la Sierra del Aconquija (e.g. Bugliani, 2008; Spano, 2011) (Figura 1). En la quebrada del Carmen, la cronología de los contextos recuperados hasta el presente en el sitio El Carmen 1 datan del siglo XIV de la Era (Coll Moritan, Cantarelli y Nastri, 2015); mientras que las excavaciones y recolecciones de material de superficie conducidas hasta el momento en el sitio El Carmen 2, así como también observaciones de la arquitectura visible en superficie, revelarían por su parte un rango de ocupación más extenso, con orígenes que se remontarían al menos hasta el período Medio, según lo atestiguado por tiestos diagnósticos recuperados en superficie (Nastri, Pratolongo, Reynoso y Vargas, 2009, pp. 718-719). De esta manera, las evidencias preliminares obtenidas en el sitio El Carmen 2 sugieren que el mismo podría constituir un caso de sitio multicomponente, especialmente útil para el estudio de la transición entre los períodos Medio e Intermedio Tardío en el valle de Santa María. Dada la escasez de estudios sobre la transición referida, así también como de casos en el valle que ofrezcan evidencias superpuestas de ambos períodos históricos, es que se consideró la pertinencia de efectuar un análisis estadístico de la cerámica de superficie del sitio a los fines de obtener un panorama más preciso acerca de las variantes representadas y sus implicancias cronológicas.

\section{Materiales y métodos}

En primer lugar, se efectuó una caracterización macroscópica y submacroscópica de la cerámica atendiendo a tres aspectos fundamentales de la misma: el tratamiento de superficie, la constitución de la pasta y la morfología (Cremonte y Bugliani, 2006-2009). Mediante la aplicación de técnicas estadísticas de análisis multivariado (cluster analysis) se realizó un agrupamiento de los casos vinculando las tres dimensiones mencionadas, desglosadas en siete variables: textura de la pasta, cocción, acabado de superficie, tipo decorativo, espesor, forma y diámetro de abertura de la boca.

La cerámica analizada proviene de recolecciones de superficie realizadas en las campañas de los años $1994^{1}$ y $2011^{2}$. En esta última temporada de trabajos se cubrió la totalidad del sitio ( $c a .6 \mathrm{ha}$ ) mediante el trazado de transectas pedestres separadas por $20 \mathrm{~m}$, recolectándose material tanto del interior como del exterior de las estructuras.

En total se recolectaron 440 fragmentos cerámicos cuyo tamaño promedio es de 11,16
2. Los materiales analizados se archivísticas de cultura material -o UACuMas- (Cantareli y Longo, 2016; Nastri, 2014), una de ellas ya

publicada: 2422-622X-37 (Nastri et
al., 2009).

publicada: 2422-622X-37 (Nastri et
al., 2009).
1. Las dos breves visitas al sitio en 1994 fueron en el marco del Proyecen el Museo Etnográfico de la UBA y bajo la dirección de la Dra. Myriam campañas, el autor senior contó con la colaboración del entonces también estudiante Marcelo Weissel. 


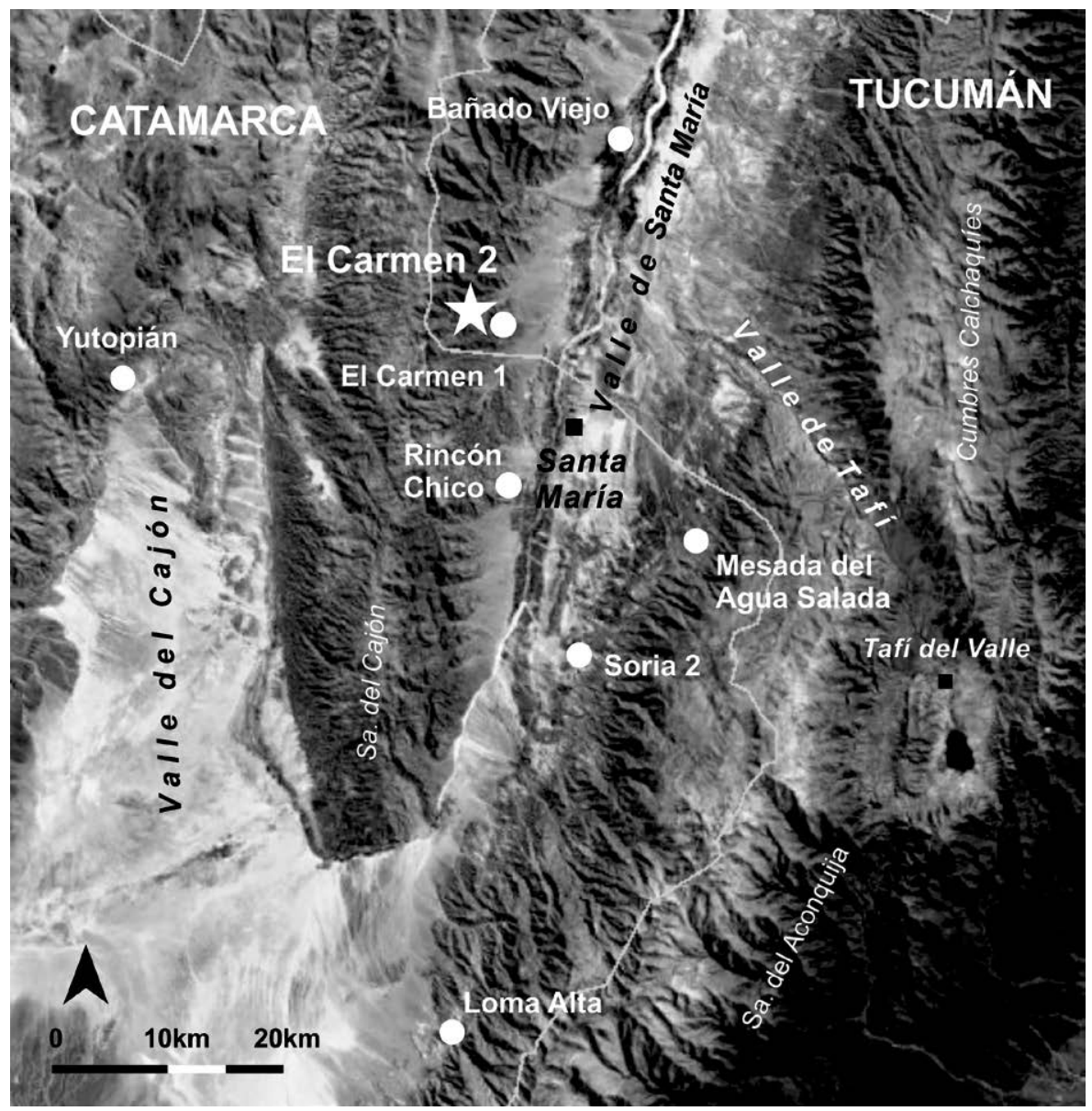

Figura 1. Ubicación del sitio El Carmen 2, Valle de Santa María (Tucumán). Círculos blancos: sitios con ocupaciones anteriores al 1000 d.C. Círculos negros: sitios con ocupaciones posteriores al 1000 d.C.

$\mathrm{cm}^{2}$, con un máximo de $71,25 \mathrm{~cm}^{2}$ y un mínimo de $1 \mathrm{~cm}^{2}$. El estado del conjunto es altamente fragmentario, la gran mayoría de los tiestos mide $6 \mathrm{~cm}^{2}$ y presenta un bajo grado de remontaje, mientras que los fragmentos erosionados no superan el $9 \%$.

A los fines de reducir los efectos de la fragmentación de la muestra se utilizó el método de Familia de Fragmentos (FF), el cual consiste en contabilizar como parte de una misma pieza aquellos fragmentos con atributos macroscópicos semejantes, tales como pasta, forma, tratamiento de superficie y espesor (Orton, Tyers y Vince, 1997). Este método es utilizado corrientemente por autores que desarrollan sus investigaciones en el valle de Santa María (Baigorria di Scala, Belotti de Medina, Carbonelli y Gaál, 2015; Palamarczuk, 2008; Spano, 2011). A partir de los 440 fragmentos recolectados, se conformaron $289 \mathrm{FF}$, de las cuales 54 corresponden a FF formadas por dos o más fragmentos y 235 a FF formadas por un único tiesto. Los fragmentos erosionados en una o ambas superficies que no pudieron ser agrupados en familias de dos o más fragmentos no se incluyeron en el análisis (40:440) debido a que en los mismos no es posible observar el conjunto de variables tomadas en cuenta.

También se efectuó el cálculo de Número Mínimo de Vasijas mediante el método de conteo de los bordes identificados. En este caso la cifra se redujo a 43, la cual sin duda subestima en demasía la cantidad de piezas que fueron utilizadas en el sitio, en función de que se trata de una muestra de superficie de un sitio con una potencia arqueológica probada de al menos $70 \mathrm{~cm}$ de profundidad. 

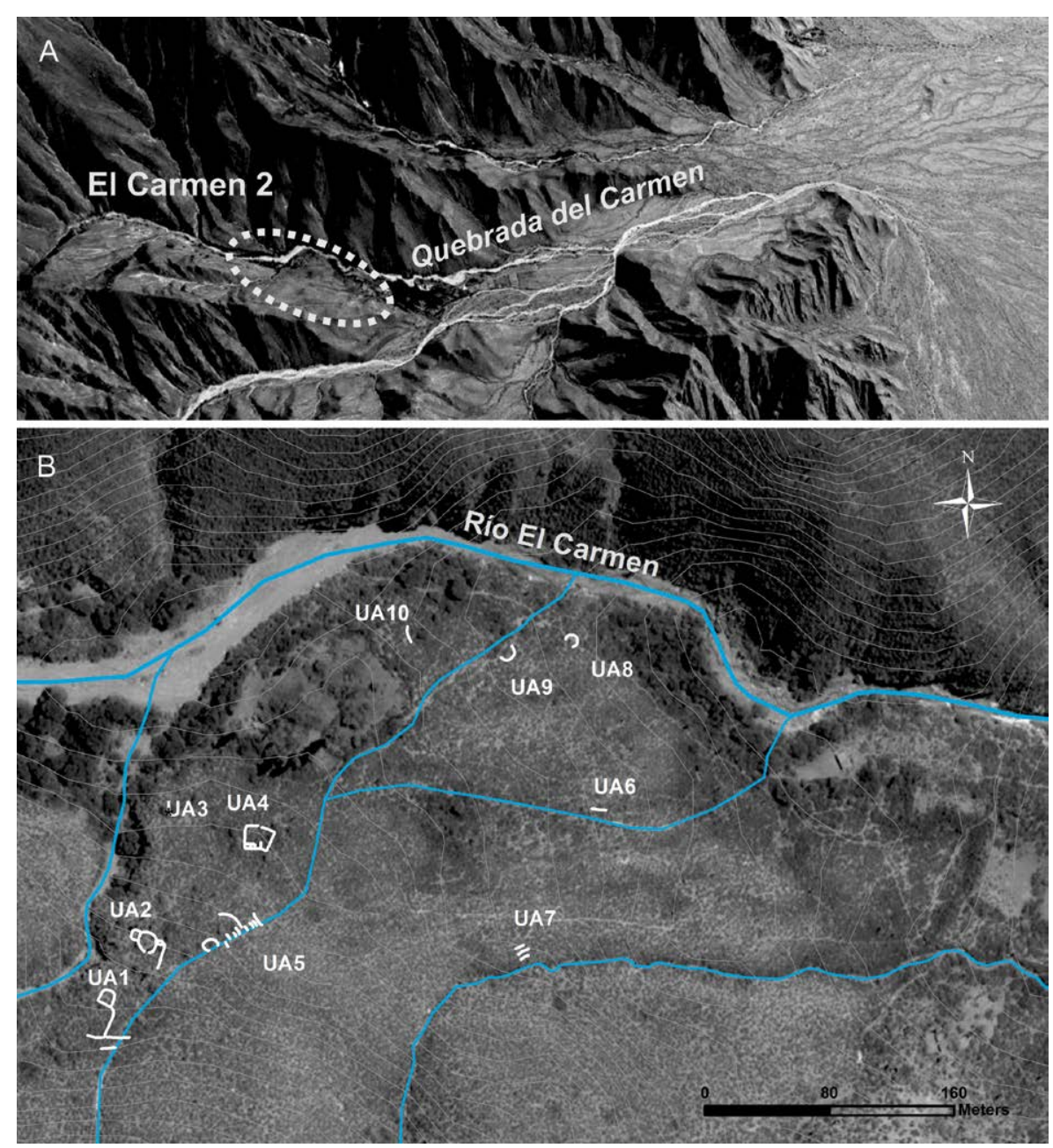

Figura 2. El Carmen 2. A) Vista aérea del sitio en la Quebrada del Carmen; B) detalle del sitio con las Unidades Arquitectónicas relevadas por Coll y Villegas en el año 2011.

\section{Análisis macroscópico y submacroscópico}

\section{Tratamiento de superficie}

Dentro de esta dimensión se incluye el acabado de la superficie, las técnicas decorativas y los motivos presentes. 1) Se entiende por acabado de superficie a las "características superficiales que resultan de la manera en que una vasija fue emparejada y suavizada durante el proceso de manufactura y subsecuentemente" (Feely, 2010, p.72). Para el acabado de superficie se distingue entre Pulido, Alisado, Peinado, Tosco, Erosionado e Indeterminado que se definen de acuerdo a la Convención Nacional de Antropología de mediados de la década del '60 (Primera Convención Nacional de Antropología, 1966). 2) Se entiende por técnicas decorativas a la presencia o ausencia de elementos o marcas tales como Pintura, Incisión, Modelado y Baño. La Pintura se considera cuando son visibles trazos o motivos producto de la aplicación de pigmentos. Se clasifica como

3. Incluye tonalidades que van desde el Blanco (Munsell 10YR 7/3) al Blanco Amarillento (Munsell 10YR $7 / 3,10 Y R 7 / 4)$.

4. Incluye tonalidades que van desde el Marrón anaranjado (Munsell 5 YR 5/6, 7.5YR 5/6) al Crema (Munsell 7.5YR 6/4). Baño cuando toda la superficie está cubierta por algún pigmento de un color diferente al de la pasta (Feely, 2010). En este sentido, no se incluyen aquellos baños que son del mismo color que la pasta. Se distinguió entre Baño Blanco ${ }^{3}$, Baño Ante ${ }^{4}$ y Baño Rojo. Bajo la categoría "Color de Superficie" se incluyen aquellas FF cuya superficie no presenta ni Baño ni Pintura, Incisión o Modelado. Fueron caracterizadas por el color de la superficie: Rojo-Marrón (incluye tonalidades desde el rojo al marrón), Ante, Marrón oscuro, Gris y Negro. En los casos en que no se puede determinar el color del baño o 
de la superficie se utilizó el término Indeterminado. 3) Se identificaron los motivos que componen el diseño (Shepard, [1956] 1985) y, en los casos en que fue posible, se definió el campo decorativo distinguiendo entre borde, cuerpo y asa.

\section{Morfología}

Dado el bajo grado de remontaje de los fragmentos, se efectuó la aproximación a las formas presentes en la muestra en base a la consideración de los bordes apelando al método convencional de la "carta de diámetros" (Rice, 1987). Se calculó el diámetro de abertura de la boca de aquellos fragmentos de borde que representan al menos el $5 \%$ del diámetro a estimar, tomando como referencia el perímetro exterior del tiesto. Se realizó el dibujo del perfil morfológico de aquellos fragmentos que pudieron ser orientados en un plano horizontal (Moreno Martín y Quixal Santos, 2012-2013). Se empleó para esto el instrumento "peine-copiador de perfiles". Sobre la base de los tipos de bordes identificados y sus dimensiones se realizó una clasificación morfológica general siguiendo las categorías propuestas por Balfet, Fauvet-Berthelot y Monzón (1992). En las piezas identificadas como de forma simple, es decir, "aquellas cuya forma puede describirse con referencia al volumen geométrico que encierran: cilindro, cono, esfera, elipsoide..." (Balfet et al., 1992, p. 35) se continuó el perfil de la pieza, dibujando la forma geométrica que más se ajustara. Así, se pudo obtener la altura e inferir la forma de acuerdo con las categorías establecidas por Balfet et al. (1992) sobre la base de criterios morfométricos. En el caso de aquellas FF donde el tipo de borde y su orientación podían corresponderse con más de una forma, la misma fue estimada a partir de la correlación con otros atributos como el diámetro de abertura, el espesor, las características submacroscópicas de la pasta, el tratamiento de superficie, utilizando como referencia aquellas formas documentadas en el valle de Santa María (Bugliani, 2008; Greco, Marchegiani y Palamarczuk, 2012; Spano, 2011).

\section{Pasta}

Se realizó la definición de los distintos grupos de pasta a través de la observación de la textura y el fondo de pasta en fracturas frescas, en lupa binocular a bajos aumentos (30X). La textura de la pasta, entendiéndola como producto de la relación entre las inclusiones no plásticas y el aspecto de la matriz arcillosa (Cremonte y Bugliani, 20062009), fue descripta teniendo en cuenta las inclusiones (principalmente su tamaño y frecuencia) y el grado de compactación de las inclusiones no plásticas con la fracción arcillosa (alto, medio, bajo). Para la identificación del tamaño de las inclusiones se utilizó la escala de clasificación granulométrica de Wentworth. El cálculo de la frecuencia de la totalidad de inclusiones presentes y del tamaño predominante se realizó a partir de fotografías procesadas en el software JMicroVision. A partir de la frecuencia y tamaño predominante de inclusiones y del grado de compactación de las mismas con la fracción arcillosa se establecieron tres categorías de textura: Fina (densidad de inclusiones menor a $30 \%$, hasta un $15 \%$ de inclusiones mayores a $0,25 \mathrm{~mm}$, grado de compactación alto), Media (densidad de inclusiones menor a 30\%, entre un 15 y un 70\% de inclusiones mayores a $0,25 \mathrm{~mm}$, grado de compactación medio) y Gruesa (densidad de inclusiones mayor a $30 \%$, entre un 15 y un $70 \%$ de inclusiones mayores a $0,25 \mathrm{~mm}$, grado de compactación bajo). El fondo de pasta o matriz arcillosa se describió teniendo en cuenta principalmente su estructura o aspecto general distinguiéndose entre dos grandes categorías que podrían ser descriptas tomando como referencia las texturas de rocas metamórficas. Si bien dichas estructuras fueron utilizadas por diversos autores en relación con la descripción de cortes delgados (e.g. Pereyra Domingorena, 2015; Puente, 2012), resultan operativas también para cortes frescos. Estructura Microgranosa es aquella "en la que se observan numerosos microcristales que dificultan la visualización 
de la fracción arcillosa", mientras que Criptofilitosa es la estructura "en la cual no se observan claramente las microlaminillas de micas y la matriz arcillosa resulta bastante compacta" (Cremonte y Pereyra Domingorena, 2013, p.13). Por último, se observaron aspectos referidos a la cocción de las piezas, a través de la caracterización de la secuencia cromática de la fractura fresca. Para ello se tomó como referencia la escala de colores de Munsell y se distinguió entre atmósfera de cocción oxidante, reductora y mixta (Feely, 2010).

\section{Análisis estadístico multivariado (cluster analysis)}

El método de análisis multivariado utilizado para este estudio fue el análisis de conglomerados (cluster analysis), realizado con el programa PAST versión 3.14 (Hammer y Harper, 2006). Se realizó un análisis de conglomerados jerárquico aglomerativo utilizando el algoritmo pares agrupados (paired groups) y Jaccard como medida de distancia. El procedimiento del análisis jerárquico aglomerativo comienza agrupando los elementos más semejantes entre sí y continua agregando elementos a dichos grupos y uniendo los grupos entre sí en niveles de similitud progresivamente menores, hasta que culmina en un único grupo con un nivel de similitud interno muy bajo. El resultado es un dendrograma o diagrama de árbol que expresa las relaciones entre los elementos y los grupos (Shennan, 1992). La distorsión producida por la técnica fue evaluada mediante el Coeficiente de Correlación Cofenética (CCC). Los valores indicadores de escasa distorsión varían entre 0,7 y 0,9. Para el análisis se tuvieron en cuenta siete variables, la mayor parte de ellas cualitativas y sólo dos cuantitativas. Tres de las variables corresponden a forma (espesor, diámetro de la boca, pieza), dos a tratamiento de superficie externa (acabado de superficie, tipo decorativo) y dos a pasta (textura, cocción). Los atributos de las variables fueron codificados de acuerdo a presencia (1) / ausencia (0) resultando en un total de 32 atributos. Las variables con sus respectivos atributos y estados son:

Forma. Espesor: 1. Fino (0 a $5 \mathrm{~mm})(0-1), 2$. Medio (5,1 a $10 \mathrm{~mm})(0-1)$. Diámetro de la boca: 3 . Muy pequeño $(6$ a $10 \mathrm{~cm})(0-1), 4$. Pequeño $(11$ a $15 \mathrm{~cm})(0-1), 5$. Mediano $(16-20 \mathrm{~cm})(0-1), 6$. Grande $(>$ a $21 \mathrm{~cm}), 7$. Indeterminado (0-1). Pieza: 8. Cuenco (0-1), 9. Escudilla (0-1), 10. Jarra (0-1), 11. Olla (0-1), 12. Tinaja (0-1), 13. Cántaro (0-1).

Tratamiento de superficie. Acabado de superficie externo: 14. Alisado (0-1), 15. Pulido (0-1), 16. Alisado y Pulido (0-1), 17. Peinado (0-1). Tipo decorativo externo: 18. Negro s/Blanco (0-1), 19. Negro s/Rojo (0-1), 20. Negro y/o Rojo s/Ante (0-1), 21. Baño Rojo (0-1), 22. Baño Blanco-Ante, 23. Baño Marrón, Gris, Negro, Indeterminado (0-1), 24. Rojo-Marrón (0-1), 25. Ante (0-1), 26. Gris-Negro (0-1).

Pasta. Textura: 27. Fina (0-1), 28. Media (0-1), 29. Gruesa (0-1). Cocción: 30. Oxidante (0-1), 31. Reductora (0-1), 32. Mixta (0-1).

Debido a que sólo en un $8,7 \%$ de los casos de la muestra fue posible determinar la forma de las piezas a las que una vez pertenecieron los fragmentos de hoy, se construyeron dos matrices básicas de datos que fueron estudiadas por separado. La primera fue elaborada en base al total de la muestra $(n=289)$, y comprende cinco variables, de las cuales dos corresponden a tratamiento de superficie externa (acabado de superficie, tipo decorativo), dos corresponden a pasta (textura, cocción) y una corresponde a forma (espesor). La segunda matriz fue conformada por las $25 \mathrm{FF}$ con bordes diagnósticos $(8,7 \%)$ que ofrecieron la posibilidad de registrar valores para todas las variables de análisis: tres correspondientes a forma (espesor, diámetro de la boca, pieza), dos a tratamiento de superficie externa (acabado de superficie, tipo decorativo) y dos a pasta (textura, cocción). Ambas matrices se analizaron desde el punto de vista de la asociación de Familias de Fragmentos (Matriz Q) y desde el punto de vista de la 
asociación de Variables (Matriz R). Esto último permitió explorar cuáles fueron las variables responsables de la discriminación de los grupos resultantes.

\section{Resultados y discusión}

\section{Análisis macroscópico y submacroscópico}

Los resultados del análisis del tratamiento de superficie se muestran en la Tabla 1. Las técnicas de pulido y alisado de la superficie externa ostentan proporciones similares en la muestra, siendo las formas predominantes. Las tonalidades más frecuentes, por su parte, son las Rojo/Marrón, las que presentan Baño Rojo o Blanco y las Ante, siendo muy escasos los fragmentos Grises y Negros. Un bajo porcentaje de casos presenta decoración, con motivos geométricos pintados, siendo menos frecuentes los casos incisos, modelados y modelados e incisos. Entre los motivos figurativos cabe destacar los P7, P13 y MI1 (Figura 3).

En cuanto a las formas representadas, el 79,2\% de las FF corresponde a partes del cuerpo de las vasijas. En total se contabilizaron 43 bordes (bordes + bordes con asas), 12 asas (asas + asas y bordes + asas y bases) y ocho bases (bases + bases y asas). La variabilidad de bordes, asas y bases se presenta en la Figura 4. Predominan piezas con borde entrante y evertido con labio convexo (Figura 4A). Los casos con diámetros de abertura de la boca pequeños, menores a $15 \mathrm{~cm}$ (19:43), son los más frecuentes. Le siguen, en segundo lugar (12:43), los indeterminados (que no llegan a representar el $5 \%$ del diámetro total de la pieza); y, a continuación, con idénticas frecuencias (6:43) los medianos de entre 16 y $20 \mathrm{~cm}$, y los grandes de entre 21 y $35 \mathrm{~cm}$. Dentro de las piezas con asas predominan aquellas acintadas de sección circular de gran tamaño, con diámetros de 20 a $30 \mathrm{~mm}$ (Figura 4B). Las bases cóncavas-convexas encontradas pertenecen en su mayoría a piezas Pulidas con Baño Rojo $(n=3)$ de espesores muy delgados de entre 5,5 y $7 \mathrm{~mm}$; el pie cilíndrico con Baño Ante pertenece a una FF que presenta además un asa otomorfa de pequeñas dimensiones; las tres bases que no han podido ser determinadas presentan espesores de entre 7 y $11 \mathrm{~mm}$ (Figura 4C). Con respecto al espesor del cuerpo de las piezas encontramos, en primer lugar, FF con espesores medios entre 5,1 y $10 \mathrm{~mm}$ (69,2\%), en segundo lugar con espesores delgados menores a $5 \mathrm{~mm}(28 \%)$, y unos pocos con espesores gruesos mayores a $10 \mathrm{~mm}(1,4 \%)$. En unas pocas FF $(1,4 \%)$ no se ha podido tomar dicha media, ya que no corresponden a partes del cuerpo de la pieza. Se pudo determinar la forma de $25 \mathrm{FF}$, de las cuales 12 corresponden a piezas cerradas y 13 a piezas abiertas. La categoría morfológica mayor representada es el Puco $(n=13)$, seguida de Escudillas $(n=3)$, Jarras $(n=3)$, Ollas $(n=$ $3)$, Tinajas $(\mathrm{n}=2)$ y un Cántaro. La mayor parte de los pucos y escudillas son abiertos $(n=13)$ de borde entrante $(n=9)$ y divergente $(n=4)$; sólo dos pucos y una escudilla son cerrados de borde entrante (Figura 5).

A partir de la relación entre la textura y la estructura del fondo de pasta se conformaron nueve grupos de pasta (Figura 6). Predominan las pastas de textura Fina y Media casi en las mismas proporciones que se presentan con fondos de pasta de estructura Microgranosa y Microgranosa-Criptofilitosa (Tabla 2). La mayoría de las FF presenta cocción oxidante (239:289), sólo unas pocas presentan cocción reductora (16:289) y mixta (34:289).

\section{Análisis estadístico multivariado (cluster analysis)}

En los agrupamientos realizados sobre las dos muestras -una comprendiendo la totalidad de las 289 FF y la segunda de sólo 25 FF- intervienen las siete variables -acabado de superficie, tipo decorativo, textura de la pasta, cocción, espesor, pieza y 


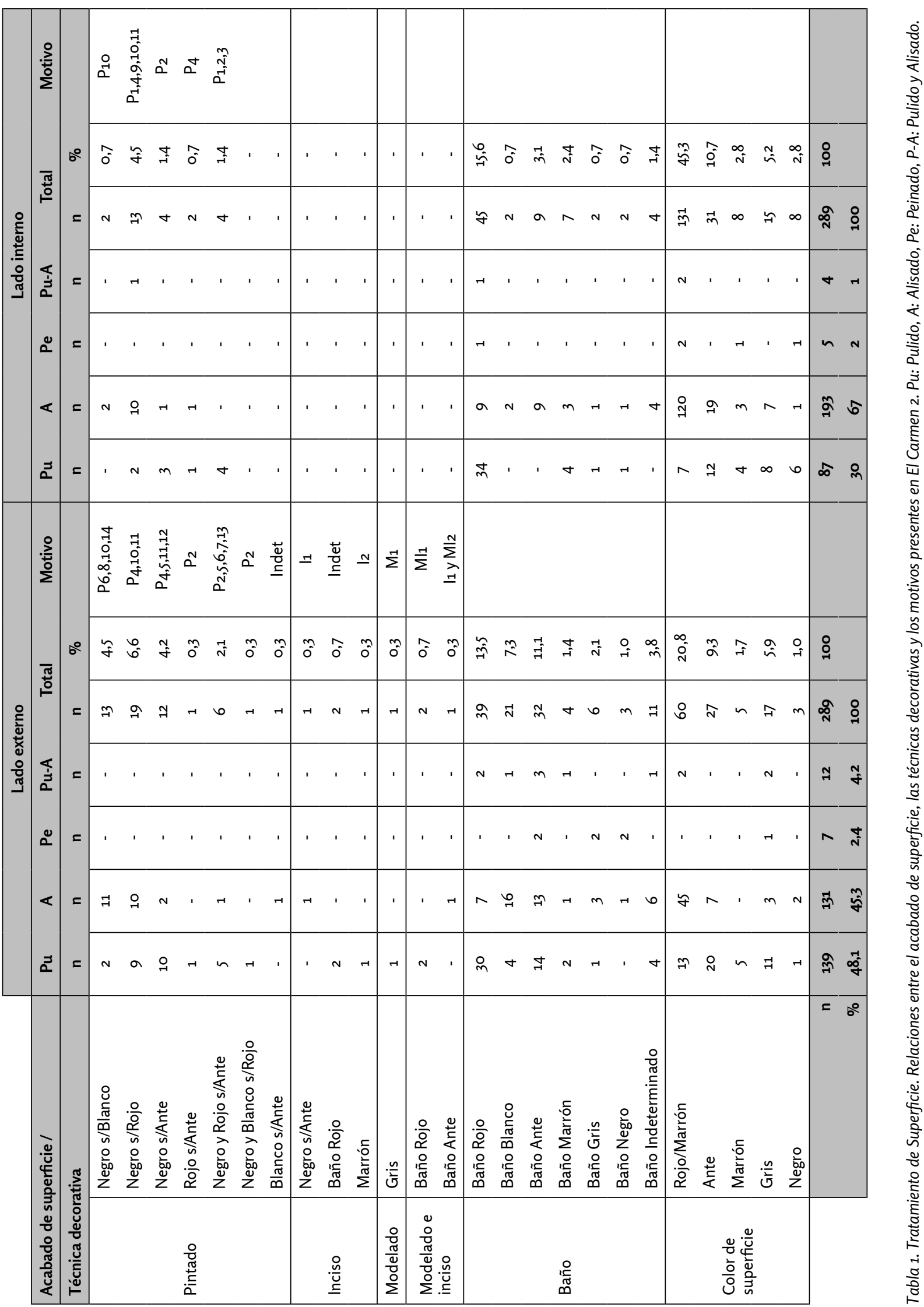




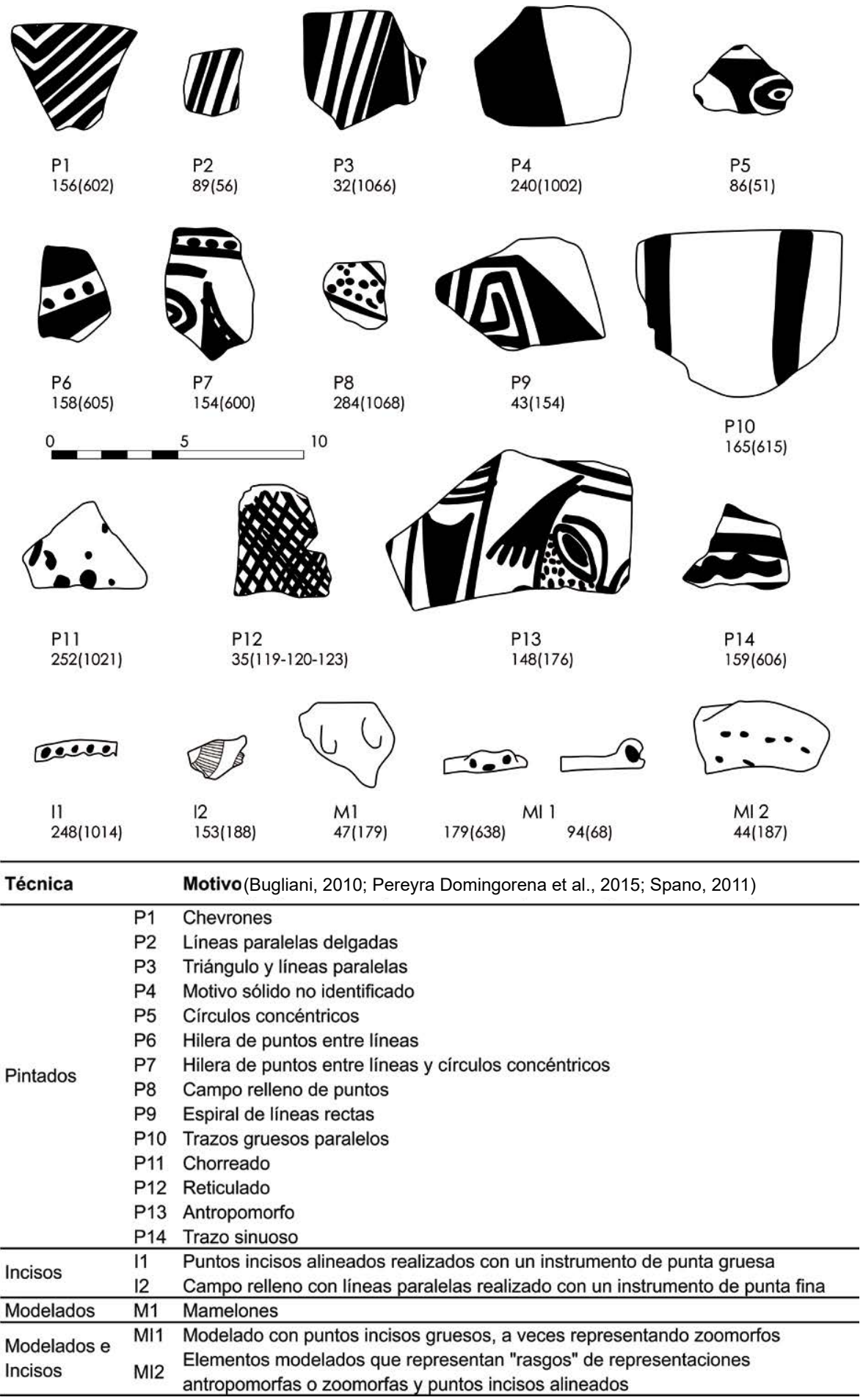

Figura 3. Motivos presentes en la cerámica del sitio El Carmen 2. En cada uno se detalla el número de FFy entre paréntesis el/los número/s de $\mathrm{F}$.

diámetro de la boca- correspondientes a las tres dimensiones de análisis: tratamiento de superficie, pasta y morfología. Los agrupamientos resultantes no difieren entre ambas muestras (Figura 7). A un bajo nivel de similitud se reconocieron dos grandes conjuntos (A-B y C-D) que comprenden casi la totalidad de la muestra $(87,5 \%)$ definidos por la cocción oxidante y dos conjuntos menores ( $\mathrm{E}$ y F) conformados por FF de cocción mixta $(4,8 \%)$ y reductora $(7,6 \%)$, respectivamente. Los dendrogramas resultantes de la matriz de asociación de variables (matriz R) (Figura 8) indican que las restantes variables 

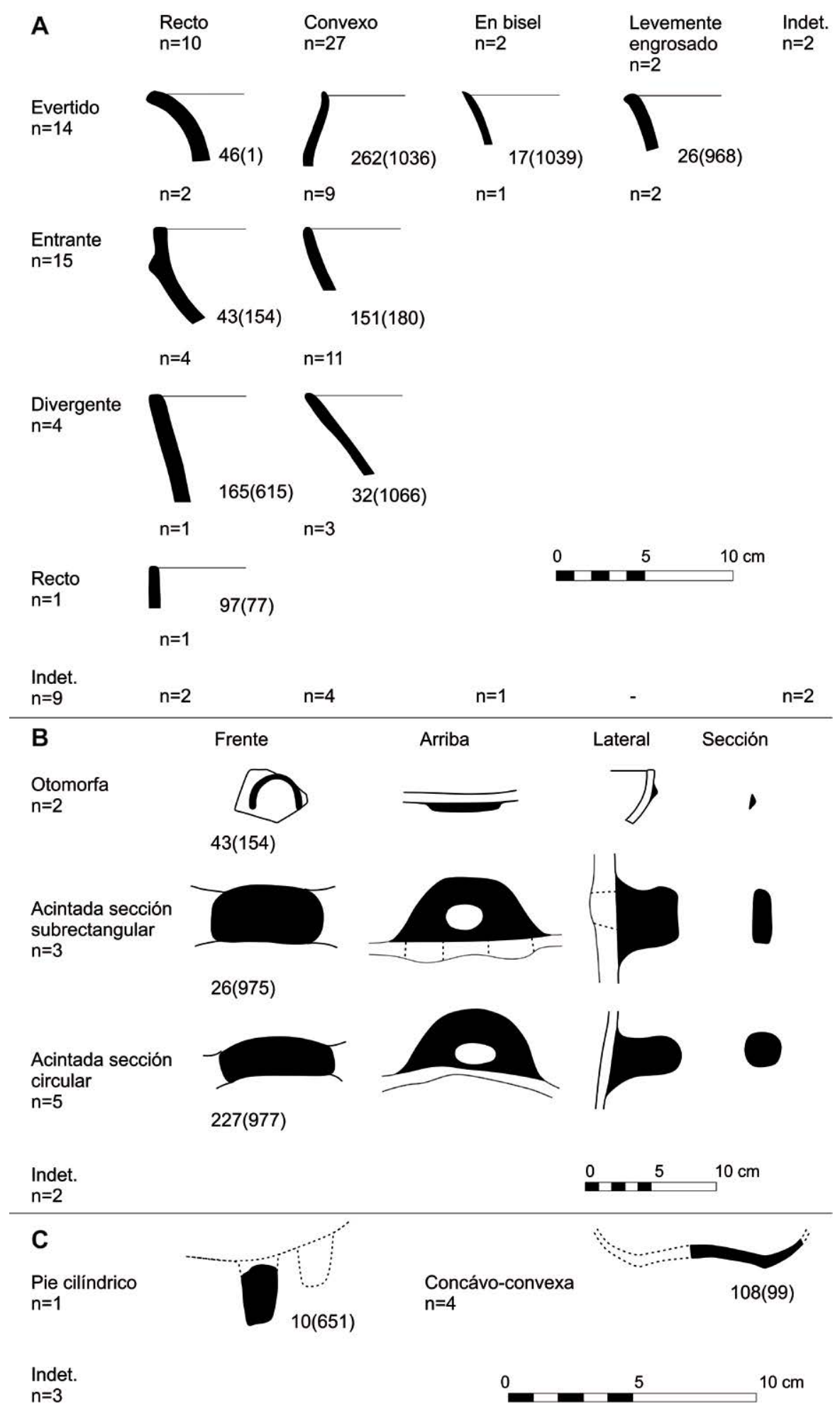

Figura 4. Variabilidad de bordes, labios, asas y bases encontradas en El Carmen 2. A) Tipos de bordes y labios; $B$ ) asas; $C$ ) bases.

fueron las responsables de la división de los conjuntos A-B y C-D. Así entonces, en el conjunto A-B se incluyen aquellas FF con pasta de textura media (A) y gruesa (B) asociadas a formas cerradas (jarras, tinajas, ollas, cántaros) de espesores mayores a 5,1 mm con acabados de superficie alisados Rojo-Marrón y Baño Blanco y en el conjunto 

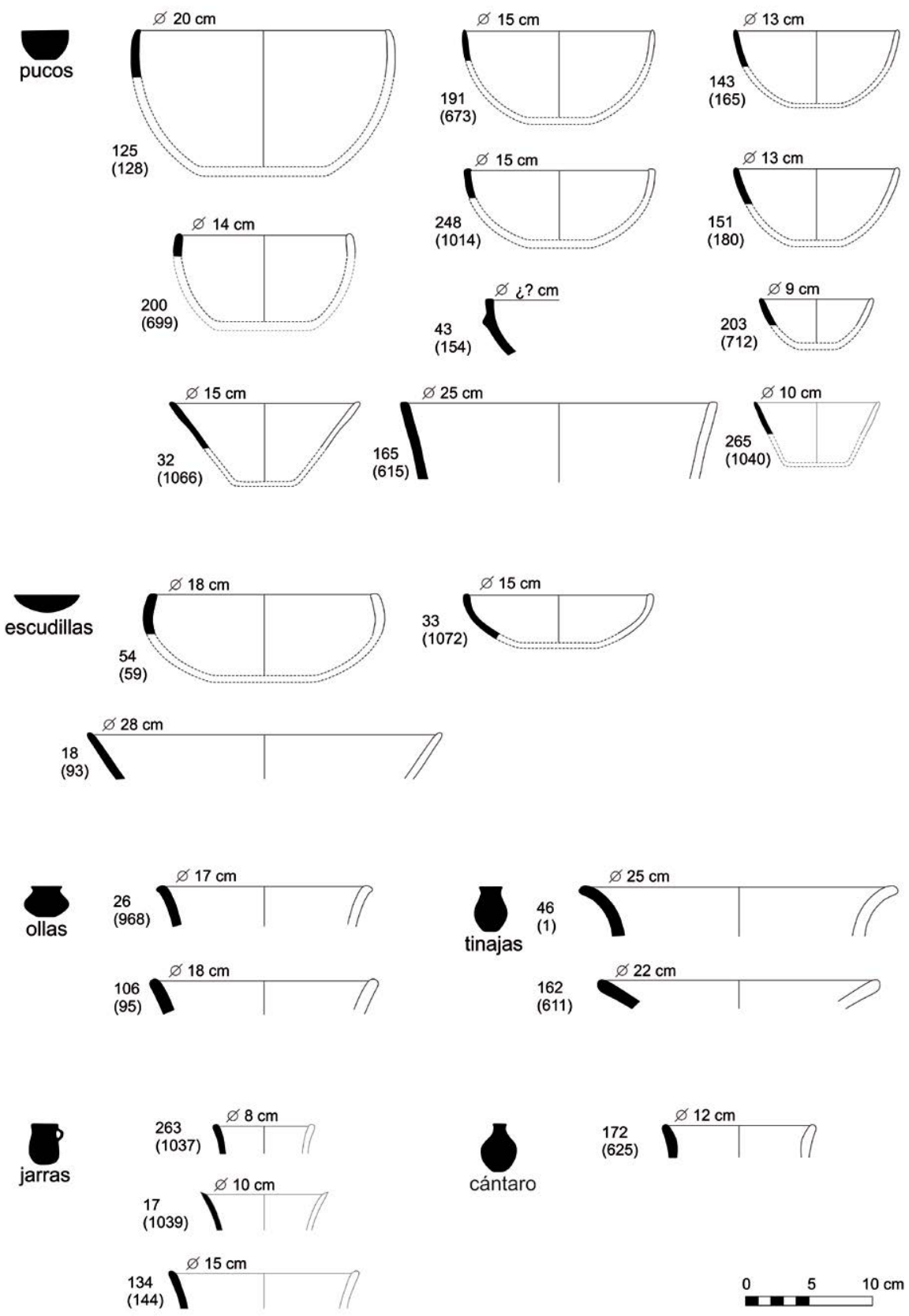

Figura 5. Categorías morfológicas presentes en El Carmen 2. En cada una se detalla el número de FFy entre paréntesis el $F$.

C-D aquellas FF con pasta de textura fina que se encuentran más fuertemente asociadas a formas abiertas (pucos) de espesores menores a $5 \mathrm{~mm}$ con acabados de superficie pulidos Ante y con Baño Rojo. A partir de la realización de un corte en un nivel de similaridad mayor a 0,5 se obtuvieron 10 grupos que se describen a continuación.

El acabado de superficie fue la variable que discriminó tres grupos internos en el subconjunto $\mathrm{A}(\mathrm{n}=88)$ : A1 con acabados alisados, A2 pulidos y A3 peinados (Figuras 8 y 9). El grupo A1 es un grupo temporalmente heterogéneo que reúne FF de estilo Santa María indeterminado (Nastri, 1999) y FF con motivos (MI2, Figura 3) similares a los que presentan algunas piezas de estilo Candelaria-Tafí (González y Núñez Regueiro, 


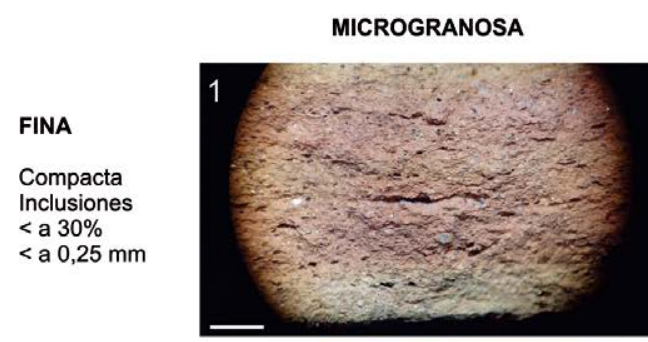

\section{MEDIA}

Semicompacta inclusiones $<$ a $30 \%$

$>$ a $0,25 \mathrm{~mm}$

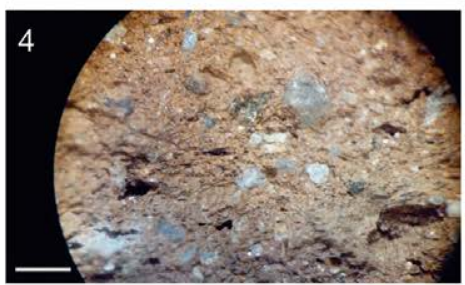

GRUESA

Poco compacta Inclusiones

$>$ a $30 \%$

$>$ a $0,25 \mathrm{~mm}$

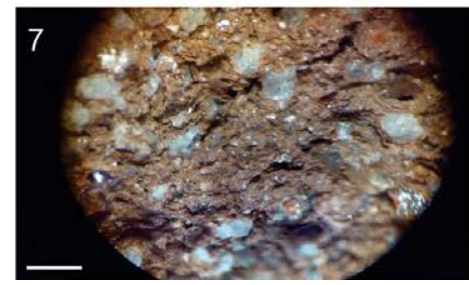

MICROGRANOSA-CRIPTOFILITOSA
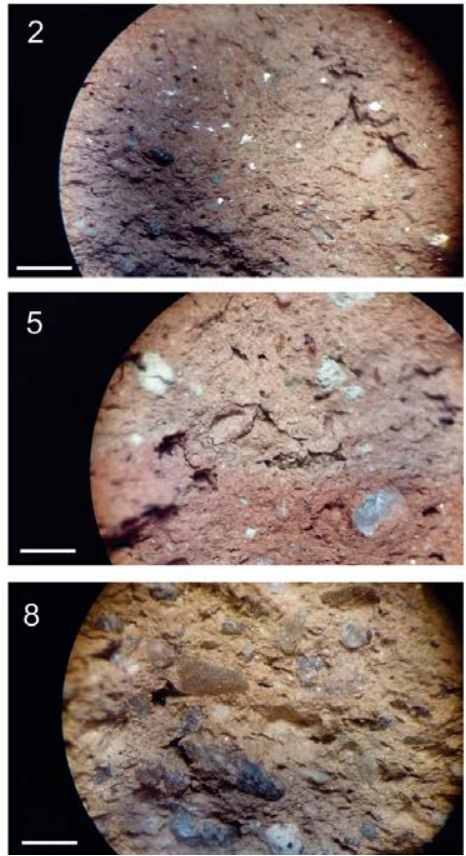

CRIPTOFILITOSA
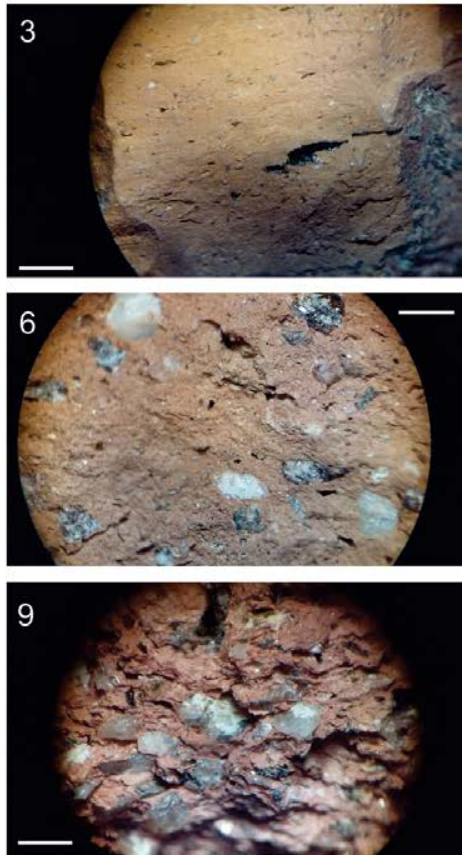

Figura 6. Grupos de pasta (3oX, escala $1 \mathrm{~mm}$ ).

\begin{tabular}{|l|c|c|c|c|c|c|}
\hline & \multicolumn{3}{|c|}{ Fondo de pasta (estructura) } & \multicolumn{2}{c|}{ Total } \\
\hline Textura & Microgranosa & $\begin{array}{c}\text { Microgranosa- } \\
\text { Criptofilitosa }\end{array}$ & Criptofilitosa & $\mathbf{n}$ & $\%$ \\
\hline Fina & 60 & 54 & 21 & 135 & 47 \\
Media & 46 & 37 & 19 & 102 & 35 \\
Gruesa & $\mathbf{2 2}$ & 16 & 14 & 52 & 18 \\
\hline \multirow{2}{*}{ Total } & $\mathbf{n}$ & $\mathbf{1 2 8}$ & $\mathbf{1 0 7}$ & $\mathbf{5 4}$ & $\mathbf{2 8 9}$ & $\mathbf{1 0 0}$ \\
\cline { 2 - 8 } & $\mathbf{\%}$ & $\mathbf{4 4 \%}$ & $\mathbf{3 7 \%}$ & $\mathbf{1 8 \%}$ & & \\
\hline
\end{tabular}

Tabla 2. Tipos de pasta presentes en El Carmen 2.

1960; Heredia, 1974). Se destaca la presencia de un cántaro con Baño Blanco que podría coincidir con los cántaros encontrados en Yutopián (1630 $\pm 60 \mathrm{AP})$, valle del Cajón (Bugliani, 2008; Gero, 2015, figura 44 y 58). Similares cántaros, con pasta de textura media pero con la superficie Alisada Naranja, fueron encontrados en el sitio Soria 2 (1940 \pm 80 AP) (Spano, 2011). Ambos tipos de cántaros, con decoración modelada e incisa, guardan similitud con el estilo Candelaria-Tafí. FF de morfología indeterminada que presentan Baño Blanco podrían corresponderse con piezas Santa María o Candelaria-Tafí. Este Baño Blanco también ha sido registrado en piezas de la Quebrada de La Ciénaga asociado a contextos del primer milenio d.C. (Cremonte, 1996) y en el sector medio de la estratigrafía del sitio Bañado Viejo donde fue descripto como característico de la fase Bañado entre los 450-600 d.C. (Scattolin, [2004] 2007). En el grupo A2 $(n=32)$ se encuentra una Jarra y una variabilidad de FF que no guardan un patrón de asociación; no se identificaron elementos diagnósticos en terminos de temporalidad. Por último, el grupo A3 $(n=5)$ reune las escasas piezas con acabado de superficie peinado con baño, tan abundantes en contextos domésticos del segundo milenio d.C. como Rincón Chico (Greco et al., 2012) y El Carmen 1 (Coll Moritan et al., 2015). 

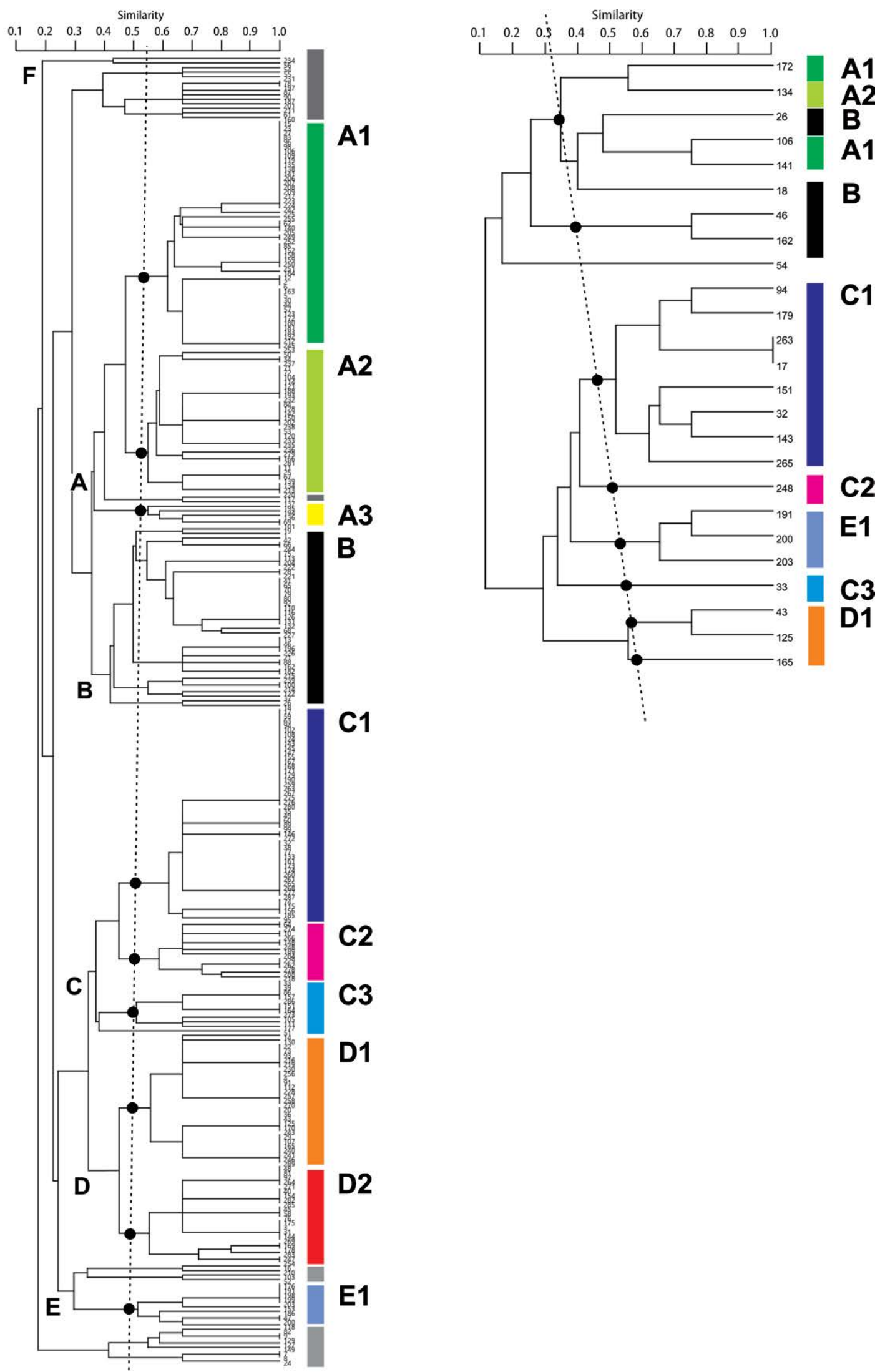

Figura 7. Dendrogramas con el agrupamiento de las FF analizadas y los grupos conformados. Izquierda 289 FF. Derecha $25 \mathrm{FF}$ correspondientes a bordes que permiten definir formas. Programa Past versión 3.14. (Hammer y Harper, 2006) Coeficiente de Correlación Cofenética (CCC): 0,7624 y o,8823 respectivamente. 

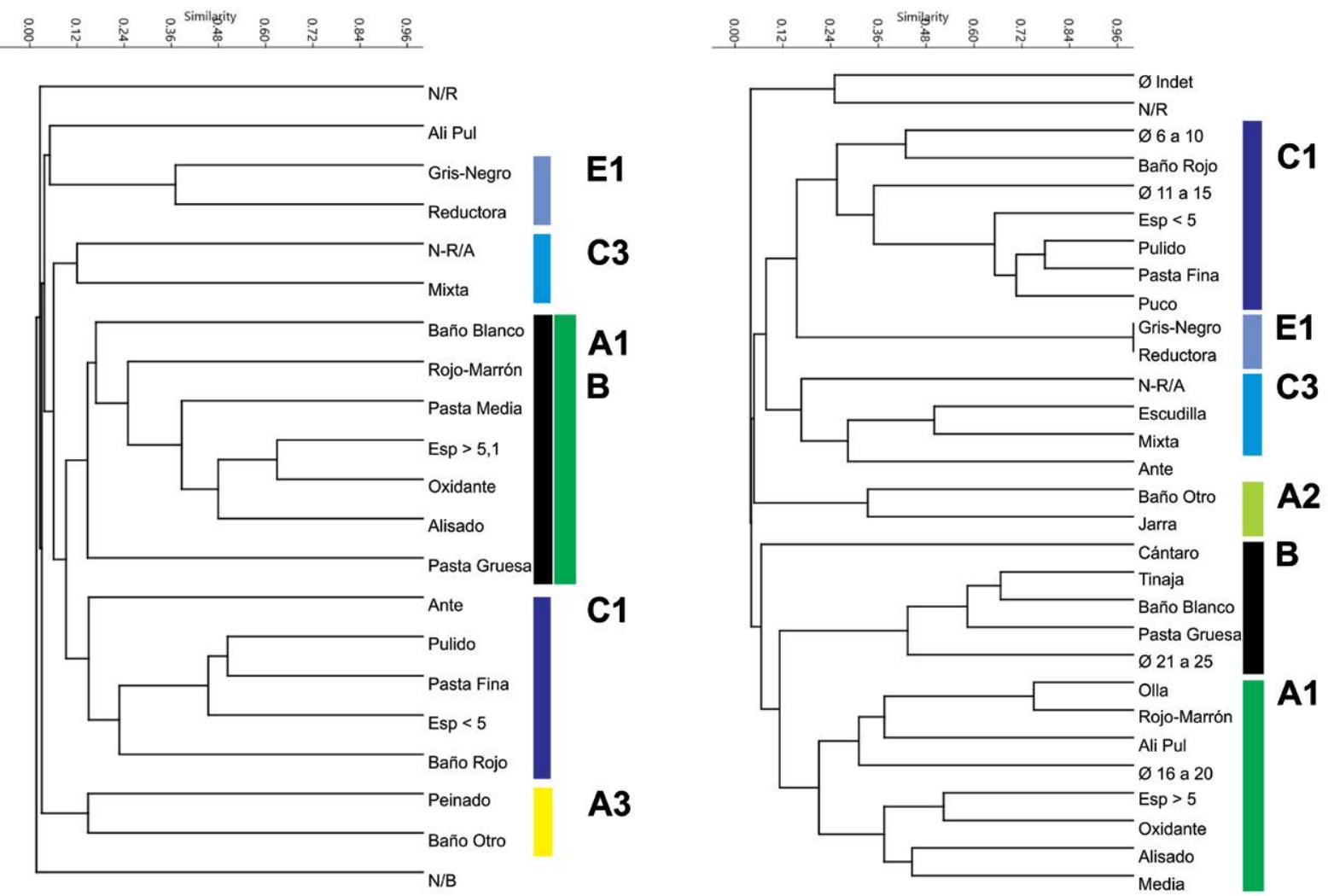

Figura 8. Dendrogramas resultantes de las matrices $R$ que muestran la asociación de variables responsables de las agrupaciones definidas. Izquierda $289 \mathrm{FF}, 5$ variables. Derecha 25 FF correspondientes a bordes que permiten definir formas, siete variables. Programa Past versión 3.14. (Hammer y Harper, 2006) Coeficiente de Correlación Cofenética (CCC): 0,8578 y o,8414 respectivamente.

El subconjunto B $(\mathrm{n}=40)$ contiene las únicas dos tinajas con Baño Blanco y una olla Rojo-Marrón, ambas con diámetros de abertura de 17 a $25 \mathrm{~cm}$ que no se pueden incluir dentro de un estilo conocido.

El subconjunto $\mathrm{C}(\mathrm{n}=72)$ reúne pequeñas piezas abiertas con diámetros de abertura de la boca menores a $15 \mathrm{~cm}$, de pasta fina muy compacta, cocidas en su mayoría en atmósfera oxidante, paredes con espesores de entre 3 y $5 \mathrm{~mm}$ y superficies esencialmente Pulidas (Figura 8). La mayor parte de ellas corresponde a estilos característicos del primer milenio d.C. y se dividen en tres grupos que presentan variaciones temporales dentro de este período (Figura 10).

En el grupo C1 $(\mathrm{n}=47)$ predominan las piezas Pulidas con Baño Rojo, con las cuales se confeccionaron pucos y jarras pequeñas. Fragmentos con este acabado de superficie se encontraron en el sitio Bañado Viejo ubicado a unos pocos $\mathrm{km}$ de El Carmen 2 en momentos anteriores al 500 d.C. (Scattolin et al., 2001) y son similares a la alfarería con terminación monocroma roja común en el valle de Tafí, aunque allí se la ha encontrado distribuida entre piezas con los tres tipos de textura de pasta (Cremonte, 1996). Esta asignación temporal, para los inicios del primer milenio, es coincidente con los pucos Baño Rojo con motivos modelados en el borde (MI1, Figura 3) hallados también en este grupo, semejantes a los pucos recuperados en los sitios Soria 2 (Spano, 2011) y Yutopián (Bugliani, 2008), aunque allí cocidos a atmósfera reductora con superficies Grises Pulidas. Asimismo, en este grupo se encuentra la casi totalidad de las piezas de estilo Vaquerías, estilo que se asocia a los primeros siglos de la era (Bugliani y Pereyra Domingorena, 2012). Ambos elementos, cerámica Vaquerías y cerámica con terminación monocroma roja se corresponden con los descriptos para la fase Chimpa 
Similarity
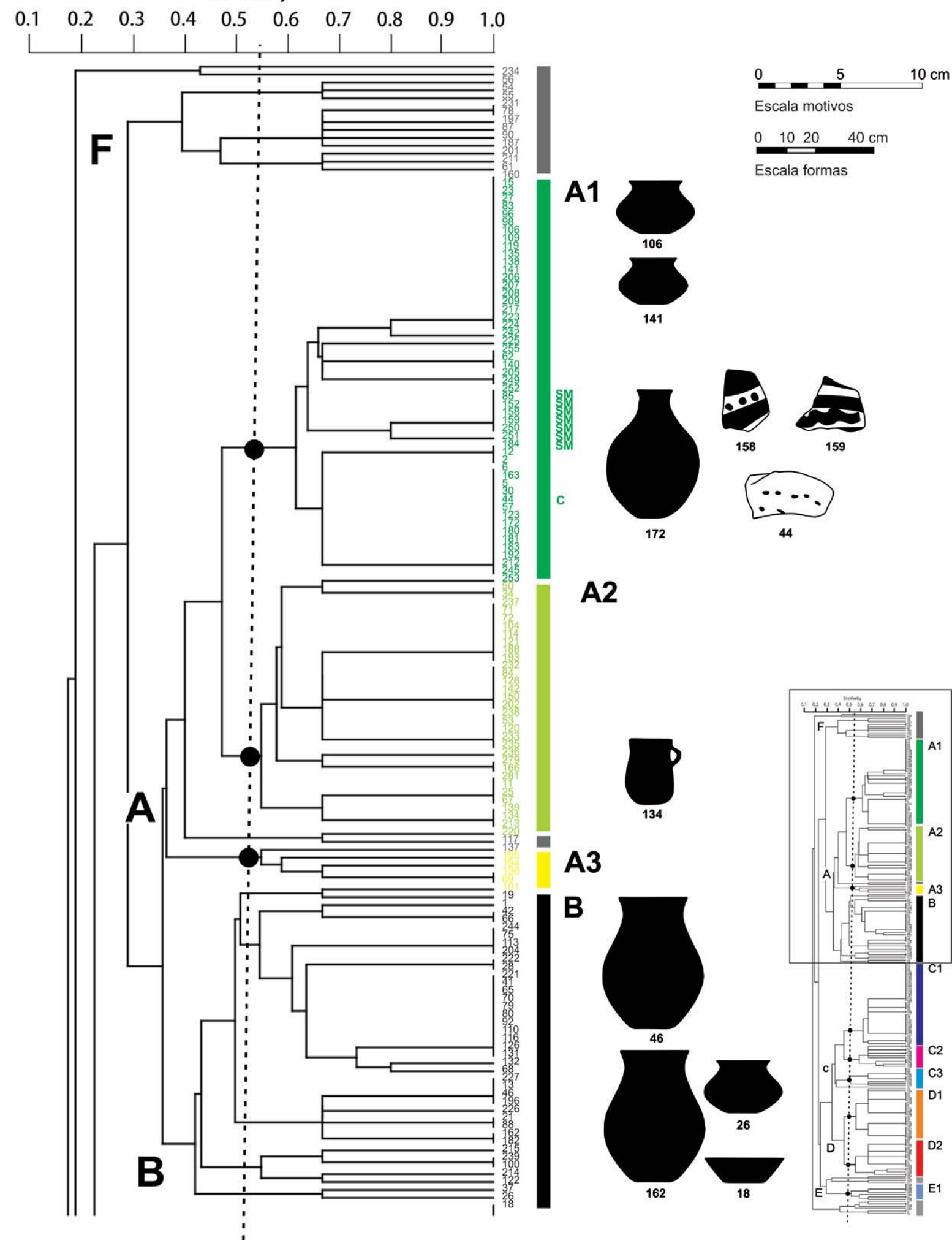

Figura 9. Detalle de los grupos conformados en los subconjuntos A y B, correspondientes a FF con pasta de textura media y gruesa, respectivamente. 


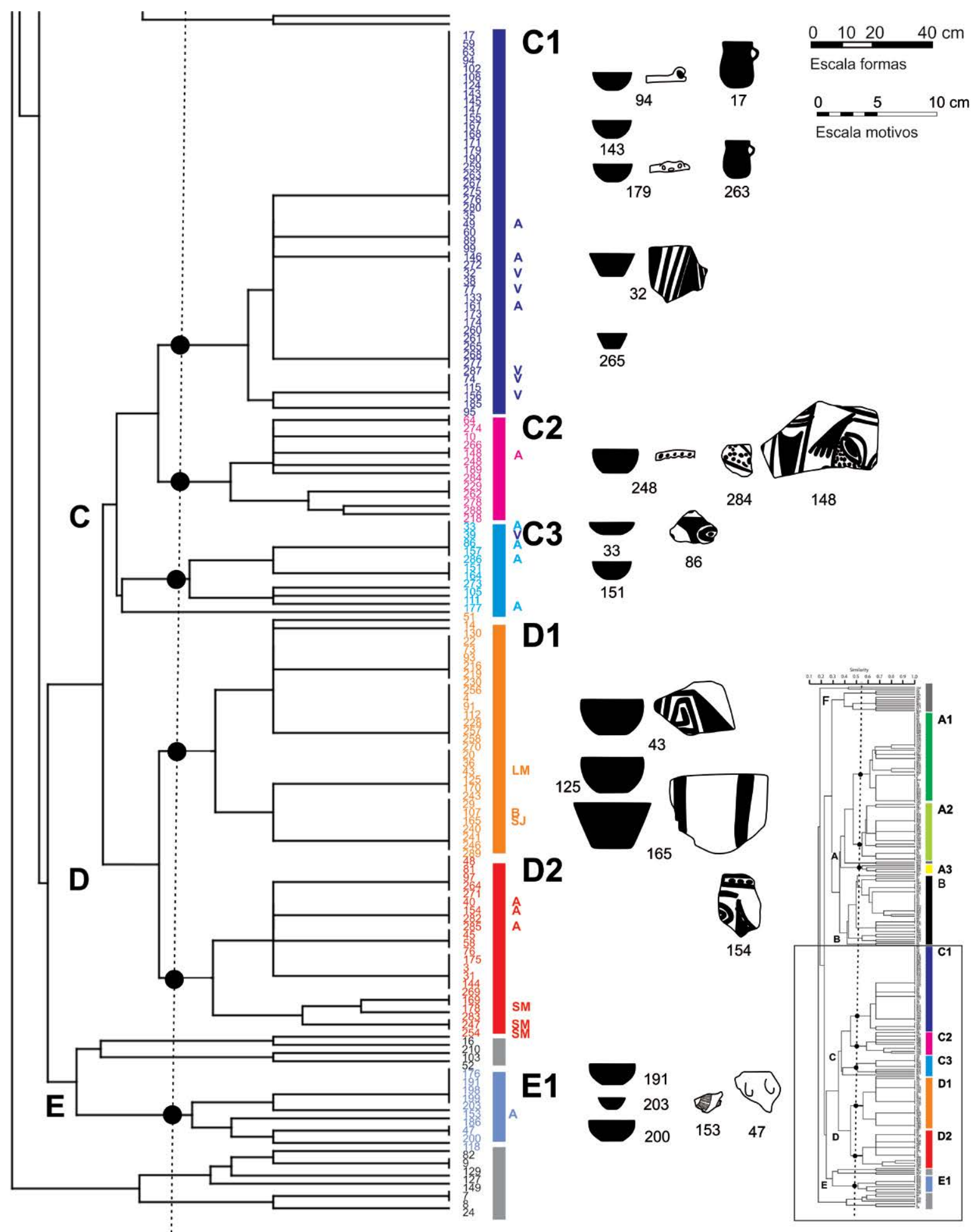

Figura 10. Detalle de los grupos conformados en los subconjuntos $C, D$ y E, correspondientes a FF con pasta de textura fina.

(Scattolin, [2004] 2007) sugiriendo también una temporalidad anterior al 450 d.C. para las piezas que componen el grupo $\mathrm{C} 1$. 
El grupo C2 $(n=13)$ contiene diversos fragmentos vinculados entre sí por estar alisados y poseer un espesor delgado. Incluye un fragmento de puco con borde inciso similar al encontrado en un contexto temprano con reutilización durante el tardio de la Mesada de Agua Salada, al sureste del valle de Yocavil (Lanzelotti y Spano, 2015), una FF Aguada con un motivo figurativo (P13, Figura 3) similar a urnas descriptas por González y Baldini (1991) y una FF con pintura Negro s/Blanco con un motivo definido por un campo relleno con puntos (P8, Figura 3) que no guarda semejanza con los motivos encontrados en piezas santamarianas.

El grupo C3 $(\mathrm{n}=12)$ se define con un grado de 0,5 de similitud por la asociación entre cocción mixta y la morfología escudilla, y, a su vez, en un grado menor de similitud, con la pintura Negro-Rojo s/Ante (Figura 8); reune a todas las piezas Aguada interior Negro Bruñido características de fines del primer milenio d.C. (Sempé y Albeck, 1981).

El subconjunto $\mathrm{E}(\mathrm{n}=10)$ fue el único que cambió su posición en ambos dendrogramas (Figura 7). Aparace como un grupo aislado en el dendrograma las $289 \mathrm{FF}$, debido a su cocción reductora, y como parte del subconjunto $\mathrm{C}$ en el de las $25 \mathrm{FF}$, por presentar morfologías pequeñas (diámetro de abertura menor a $15 \mathrm{~cm}$, espesor menor a $5 \mathrm{~mm}$ ), abiertas (puco) y con acabados de superficie pulidos (Figura 8). En él se encuentran tres pequeños pucos Gris Pulido de cocción reductora y FF de morfología indeterminada con el mismo tratamiento de superficie que aparece asiduamente durante inicios del primer milenio d.C. La FF 153 presenta decoración incisa que podría corresponderse con Aguada Inciso coincidente con una temporalidad anterior al 1000 d.C. (González, 1998). Resulta llamativa la baja frecuencia de las FF que componen este grupo a diferencia de lo que ocurre en los sitios Soria 2 (Spano, 2011) y Loma Alta (Bugliani, 2008), donde dentro del conjunto de pasta Fina predominan las alfarerías Gris Pulidas.

El subconjunto $\mathrm{D}(\mathrm{n}=51)$ reúne piezas abiertas con diámetros mayores a $15 \mathrm{~cm}$, de pasta fina, cocidas en atmósfera oxidante, con paredes de espesores entre 5 y 7 mm y superficies Pulidas y Alisadas. La mayor parte de ellas corresponde a estilos característicos del segundo milenio d.C. Este subconjunto se divide en dos grupos, uno de ellos temporalmente homogéneo y otro con heterogeneidades (Figura 10). En el grupo D1 $(n=29)$ encontramos los estilos característicos de inicios del segundo milenio d.C. como Loma Rica bicolor y San José. Este grupo incluye también FF de estilo Belén (Wynveldt, 2008) y un procentaje de FF Negro s/Rojo que no han podido ser identificadas con algún estilo en particular. En el grupo de D2 $(n=22)$ encontramos una asociación de piezas Aguada y Santa María vinculadas por su espesor mayor a $5 \mathrm{~mm}$. La FF 154 presenta una peculiar combinación de motivos utilizados en la representación de la figura humana (P7, Figura 3): ojos formados por los círculos concéntricos típicos aguada (González, 1998) y una hilera de puntos entre líneas, como es frecuente en urnas y pucos santamarianos (Marchegiani, 2008). El subconjunto D estaría de esta manera exhibiendo una continuidad tanto tecnológica como iconográfica entre fragmentos correspondientes a piezas que pudieron tener funciones y roles similares en sus respectivos contextos históricos contiguos sucesivos.

Las matrices $\mathrm{R}$ de ambos universos de análisis (Figura 8) muestran que los tipos decorados Negro s/Rojo y Negro s/Blanco no aparecen estrechamente vinculados a las otras variables analizadas. Es decir, pueden encontrarse con acabados de superficie pulidos o alisados, en piezas con espesores mayores o menores a $5 \mathrm{~mm}$, así como con pastas de textura fina o media. Si bien en general la pintura Negro s/Blanco y Negro s/Rojo se asocia con estilos tardíos, en El Carmen 2 aparecen también en piezas con atributos que de acuerdo con el análisis realizado serían característicos del primer milenio d.C., i.e. espesores menores a $5 \mathrm{~mm}$, pulidas y con pastas de textura fina muy compactas. Las FF 146, 276 (grupo C1) y 284 (grupo C2) presentan una peculiar combinación de paleta de colores del período tardío con espesores menores a $5 \mathrm{~mm}$, 
superficies pulidas y pastas de textura fina muy compactas, atributos estos últimos característicos del primer milenio d.C. La presencia de piezas con pintura Negro s/ Rojo y Negro s/Blanco en el subconjunto C podría indicar una continuidad temporal que trasciende períodos, en este caso, en relación con el uso del color.

\section{Consideraciones finales}

El estudio sistemático de la cerámica del sitio El Carmen 2 por medio de la combinación de análisis macroscópicos y técnicas estadísticas multivariadas (cluster analysis) considerando a las piezas en sus tres dimensiones (tratamiento de superficie, pasta y morfología) permitió obtener un primer acercamiento al repertorio de variantes elaboradas $\mathrm{y} / \mathrm{o}$ producidas por los ocupantes del sitio a lo largo del período analizado (0-1400 d.C.). Los patrones de confección y/o consumo exhiben una variedad que no se reduce a una sola temporalidad, al tiempo que también exhiben continuidades en distintos aspectos de las tradiciones de manufactura.

A partir del ordenamiento de las vasijas se identificaron 10 grupos con similitud mayor a 0,5 , de los cuales seis fueron significativos para acercarnos a la temporalidad: C1, C2, C3, D1, D2, E1, todos ellos de pasta fina. Los estilos característicos del primer milenio aparecen agrupados en los dendrogramas en los grupos C1, C2, C3 y E1. Los estilos característicos del segundo milenio aparecen en los grupos D1 y D2. Esto sugeriría que las FF de los grupos $\mathrm{C} 1, \mathrm{C} 2, \mathrm{C} 3$ y E1 que no han podido ser identificadas con algún estilo conocido podrían corresponder a piezas del primer milenio debido a que comparten con los estilos conocidos atributos como el espesor $(\leq 5 \mathrm{~mm})$, acabado de superficie (pulido), dimensión de la abertura pieza $(\leq 15 \mathrm{~cm})$ y tamaño (pequeño). Del mismo modo, aquellas FF de los grupos D1 y D2 podrían pertenecer a piezas características del segundo milenio d.C. debido a que comparten con los estilos conocidos atributos como el espesor ( $5 \geq 7 \mathrm{~mm}$ ), acabado de superficie (alisado y pulido), dimensión de la abertura pieza $(\geq 15 \mathrm{~cm}$ ) y tamaño (mediano). Siendo así, del total de cerámica fina $(\mathrm{n}=133)$, el $38,3 \%$ correspondería al segundo milenio y el $61,7 \%$ al primer milenio d.C. Luego, profundizando la observación a través de los agrupamientos consolidados a partir del análisis cluster, podemos desagregar estas primeras asociaciones en cuatro momentos temporalmente diferenciados, tres de los cuales presentan fuerte consistencia interna $(a, b, d)$ y uno, en cambio, presenta un carácter heterogéneo $(c)$ :

a) Temprano (Grupos C1 y E1), con una representación del 42,8\% (cocción oxidante y reductora, pasta fina muy compacta, espesor menor a $5 \mathrm{~mm}$, diámetro de la boca 7-15 cm, pulida, Vaquerías, Baño Rojo, Borde modelado, Gris, Aguada Inciso).

b) Medio (Grupo C3), con una representación del 9,1\% (cocción mixta, pasta fina muy compacta, espesor menor a $5 \mathrm{~mm}$, diámetro de la boca $13-15 \mathrm{~cm}$, Aguada Pintado/Interior negro bruñido).

c) Medio e Intermedio Tardío (Grupos C2 y D2), con una representación del 26,3\% (C2: cocción oxidante, pasta fina, espesor menor a $5 \mathrm{~mm}$, alisado, diámetro de la boca 13-15 cm, Negro s/Blanco, Aguada figurativo; D2: cocción oxidante, pasta fina, espesor mayor $5 \mathrm{~mm}$, pulido, diámetro de la boca indeterminado, Aguada Pintado figurativo, Santa María).

d) Intermedio Tardío (Grupo D1), con una representación del 21,8\% (cocción oxidante, pasta fina, espesor mayor $5 \mathrm{~mm}$, alisado, diámetro de la boca $20-25 \mathrm{~cm}$, Loma-Rica, San José).

El análisis sistemático de la evidencia cerámica de superficie permitió, por un lado, ampliar el panorama cuantitativo existente respecto de la presencia de fragmentos 
característicos de distintos momentos históricos (Nastri et al., [2004] 2009), a la vez que la asociación en los agrupamientos de cluster de fragmentos no-diagnósticos con diagnósticos, así también como de fragmentos característicos de momentos históricos contiguos invitan a la discusión acerca de los modos en que se conformaban los repertorios completos de variantes cerámicas vigentes en cada época, y cómo las tradiciones alfareras se fueron transformando a lo largo del tiempo. Si el notable crecimiento de las investigaciones arqueológicas en Argentina en las últimas décadas posibilitó afianzar las cronologías radiocarbónicas y con esto, la precisión de los períodos definidos, hoy se presenta como desafío el comprender cómo se operaron las transiciones entre uno y otro lapso cronológico. El conocimiento de la variedad cerámica en sitios vallistos no cubiertos masivamente por la evidencia de los demográficamente más densos momentos tardíos se revela como una vía promisoria para la discriminación detallada de los atributos significativos de los bienes materiales y el seguimiento de los ritmos y modos en que se operaron sus cambios a lo largo del tiempo.

\section{Agradecimientos}

A los participantes de las campañas de los años 2011 y 2012: Mariana Boveda, Violeta Cantarelli, Victoria Coll Moritan, María Amelia González, Mariel Grattone, Romina Taccone, Eugenia Turk, Ana Vargas, Paula Villegas. Al Maestro Claudio Machado, director de la Escuela Cnel. Murga de El Carmen, y a todo el personal y alumnos de dicha escuela por la hospitalidad brindada. A la Municipalidad de Santa María (Catamarca) por el apoyo brindado para el alojamiento en la ciudad. Este documento es resultado del financiamiento otorgado por el Estado Nacional (por lo tanto queda sujeto al cumplimiento de la Ley No 26.899), a través de los siguientes subsidios de investigación: ANPCyT, FONCYT PICT 2008-1428; CONICET, PIP 2010-282. 


\section{Q Referencias citadas}

» Álvarez Larrain, A. (2016). Paisajes agroalfareros del primer y Segundo milenio D.C. en la Mesada de Andalhuala Banda (Yocavil, Noroeste Argentino). Nawpa Pacha, 36(2), 161-184.

" Baigorria Di Scala, L. J., Belotti de Medina, C., Carbonelli, J. P. y Gaál, E. G. (2015). A la luz del hogar: vestigios de la comunidad doméstica formativa en el sitio Soria 2, Valle de Yocavil (Catamarca). En M. A. Korstanje, M. Lazzari, M. Basile, F. Bugliani, V. Lema, L. Pereyra Domingorena y M. Quesada (Eds.), Crónicas materiales precolombinas. Arqueología de los primeros poblados del Noroeste Argentino (pp. 519-548). Ciudad Autónoma de Buenos Aires: Sociedad Argentina de Antropología.

» Balfet H., Fauvet-Berthelot, M. F. y Monzón, S. (1992). Normas para la descripción de vasijas cerámicas. México: Centre d'Études Mexicaines et Centroamericaines (CEMCA).

» Berberián, E. y Nielsen, A. (1988). Sistemas de asentamiento prehispánico en la etapa Formativa del valle de Tafí (Pcia. De Tucumán-Rep. Arg.). En E. Berberián, (Ed.), Sistemas de Asentamiento Prehispánicos en el Valle de Tafí (pp. 21-5o). Córdoba: Comechingonia.

" Bugliani, M. F. (2008). Consumo y representación en el sur de los valles Calchaquíes (Noroeste Argentino): Los conjuntos cerámicos de las aldeas del primer milenio A.D. Oxford: BAR International Series S1774, Archaeopress.

»Bugliani, M. F. y Pereyra Domingorena, L. (2012). Una aproximación estilísticotecnológica a la cerámica polícroma "vaquerías" del Noroeste argentino. Estudios Atacameños, 43, 121-138.

" Cantarelli, V. y Longo, A. (2016). Una propuesta archivística puesta en marcha. Cultura material de sitios serranos en la provincia de Catamarca. Fragmentos del pasado-do pasado, 1, 45-80.

»Coll Moritan, V., Cantarelli, V. y Nastri, J. (2015). El Carmen 1, un poblado intermedio tardío en el valle de Santa María (prov. de Tucumán). Revista del Museo de Antropología, $8(1), 105-114$.

»Cremonte, M. B. (1996). Investigaciones arqueológicas en la quebrada de La Ciénega. (Dpto. de Tafí, Tucumán). (Tesis Doctoral inédita), Universidad Nacional de La Plata, Argentina.

» Cremonte, M. B. y Bugliani, M. F. (2006-2009). Pasta, forma e iconografía. Estrategias para el estudio de la Cerámica arqueológica. Xama, 19/23, 239-262.

"Cremonte, M. B. y Pereyra Domingorena, L. (2013). Atlas de pastas cerámicas arqueológicas: petrografía de estilos alfareros del NOA. San Salvador de Jujuy: Universidad Nacional de Jujuy.

»Feely, A. (2010). Estilos tecnológicos y tradiciones cerámicas del Bolsón de Fiambalá (Dto. Tinogasta, Catamarca). (Tesis Doctoral inédita), Universidad de Buenos Aires, Argentina.

"Gero, J. M. (2015). Yutopian. Archaeology, Ambiguity and the Production of Knowledge in Northwest Argentina. Austin: University of Texas Press.

» González, A. R. (1998). Cultura La Aguada del Noroeste Argentino (500-90o d.C.) 35 años después de su definición. Buenos Aires: Filmediciones Valero.

" González, A. R. y Baldini, M. (1991). Función y significado de un ceramio. Boletín del Museo Chileno de Arte Precolombino, 5, 23-52.

» González, A. R. y Núñez Regueiro, V. (1960). Preliminary report on archaeological research in Tafi del Valle. Akten des 34 Iternationalen Amerikanisten Kongress, 18-25. 
» Greco, C., Marchegiani, M. y Palamarczuk, V. (2012). Tipologías estilísticas e inferencias funcionales de objetos cerámicos en momentos tardíos del noroeste argentino. En M. P. Babot, M. Marschoff y F. Pazzarelli (Eds.), Las manos en la masa. Arqueologías, Antropologías e Historias de la Alimentación en Suramérica (pp. 505-526). Córdoba: Universidad Nacional de Córdoba.

» Hammer, Ø. y Harper, D. A. T. (2006). Paleontological Data Analysis. Malden: Blackwell.

» Heredia, O. (1974). Investigaciones arqueológicas en el sector meridional de las selvas occidentales. Revista del Instituto de Antropología, 5, 73-118.

» Lanzelotti, S. L. y Spano, R. C. (2015). La multitemporalidad del paisaje en la Mesada del Agua Salada (Catamarca, Argentina). Arqueología, 21(1), 47-71.

» Marchegiani, M. (2008). Estilo y cronología. Los cambios en la cerámica funeraria de Rincón Chico entre los siglos X y XVII DC. En M. Tarragó y L. R. González (Eds.), Estudios arqueológicos en Yocavil (pp. 127-175). Buenos Aires: Asociación de Amigos del Museo Etnográfico.

» Moreno Martín, A. y Quixal Santos, D. (2012-2013). Bordes, bases e informes: el dibujo arqueológico de material cerámico y la fotografía digital. Arqueoweb, 14, 178-214.

» Nastri, J. (1997-1998). Patrones de asentamiento prehispánicos tardíos en el sudoeste del valle de Santa María (noroeste argentino). Relaciones de la Sociedad Argentina de Antropología, XXII-XXIII, 247-270.

» Nastri, J. (1999). El estilo cerámico Santamariano de los Andes del Sur (siglo XI a XVI). Baessler-Archiv. Neue Folge, XLVII, 361-396.

» Nastri, J. (2014). Investigadores, habitantes locales y restos arqueológicos. En M. C. Rivolta, M. Montenegro, L. Menezes Ferreira yJ. Nastri (Eds.), Multivocalidad y activaciones patrimoniales en Arqueología. Perspectivas desde Sudamérica (pp. 257-285). Buenos Aires: Fundación de Historia Natural Félix de Azara.

» Nastri, J., Pratolongo, G., Reynoso, A. y Vargas, A. M. ([2004] 2009). Arqueología en la Sierra del Cajón: poblados, corrales y pinturas. Actas del XV Congreso Nacional de Arqueología Argentina, 251-270.

» Orton, C., Tyers, P. y Vince, A. (1997). La cerámica en arqueología. Barcelona: Editorial Crítica.

»Palamarczuk, V. (2008). Un análisis de la cerámica arqueológica de cuatro sitios en el bajo de Rincón Chico. En M. Tarragó y L. González (Eds.), Estudios Arqueológicos en Yocavil (pp. 7-17). Buenos Aires: Asociación de Amigos del Museo Etnográfico.

» Pereyra Domingorena, L. (2015). Estudio petrográfico de la cerámica Arqueológica del primer milenio d.C. al sur de los valles calchaquíes (Noroeste Argentino). Chungara. Revista de Antropología Chilena, 47(3), 415-428.

» Primera Convención Nacional de Antropología (1966). Primera Parte. Cerámica. Córdoba: Universidad Nacional de Córdoba, Dirección General de Publicaciones.

»Puente, V. (2012). Prácticas de producción alfarera durante el Tardío prehispánico en el valle del Bolsón. Un aporte desde la tecnología cerámica del sitio El Duraznito (Belén, Catamarca, Argentina). Arqueología, 18, 101-129.

» Rice, P. M. (1987). Pottery Analysis: a sourcebook. Chicago: The University of Chicago Press.

»Scattolin, M. C. ([2004] 2007). Santa María antes del año mil. Fechas y materiales para una historia cultural. En V. Williams, B. Ventura, A. Callegari y H. Yacobaccio (Eds.), Sociedades Precolombinas Surandinas: temporalidad, interacción y dinámica cultural del NOA en el ámbito de los Andes Centro-Sur (pp. 203-221). Buenos Aires: Universidad de Buenos Aires. 
» Scattolin, M. C., Bugliani, M. F., Izeta, A. D., Lazzari, M., Pereyra Domingorena, L. y Martínez, L. (2001). Conjuntos materiales en dimensión temporal. El sitio Formativo “Bañado Viejo” (Valle de Santa María, Tucumán). Relaciones de la Sociedad Argentina de Antropología, XXVI, 167-192.

» Sempé, M. C. y Albeck, M. E. (1981). La Cerámica de interior negro bruñido en el NO argentino. Su ubicación espacio-temporal y cultural. Revista Española de Antropología Americana, XI, 161-181.

»Shennan, S. (1992). Arqueología cuantitativa. Barcelona: Crítica.

" Shepard, A. O. ([1956] 1985). Ceramics for the Archaeologist. Washington D.C.: Carnegie Institution of Washington.

"Spano, R. (2011). Primera sistematización de las características estilísticas de la alfarería fina del sitio Soria 2 (Valle de Yocavil, Noroeste argentino). Revista del Museo de Antropología, 4, 127-144.

»Wynveldt, F. (2008). Tecnología cerámica Belén: caracterización macroscópica y conceptualización en la manufactura alfarera. Intersecciones en Antropología, 9, 157-172. 